\title{
Mapping European Performing Arts Databases: An Inventory of Online Historical Theatre Data Projects
}

Over the last two decades, a growing number of databases have been published online that record historical information on the production, distribution and reception of performing arts. The aim of this contribution is to present a starting inventory of European performing arts databases that are available online, since no such overview exists to date.

This inventory stems from a project carried out in 2018 at the University of Amsterdam, in the context of the digital humanities research program CREATE. ${ }^{1}$ One of the goals of the project was to examine the potential of transnational and cross-sectoral cooperation on historical research into performing arts: can we connect datasets in a meaningful way to facilitate comparative and interdisciplinary research? The first step in this project has been the creation of an inventory of online databases on theatre, music and film. ${ }^{2}$ This contribution focuses only on performance-related databases in the field of theatre and related art forms such as opera and music theatre, as these comprised the majority of our initial inventory effort. We are aware that an overview of performing arts databases will never be complete or even up to date, but we nevertheless do believe that our compiled overview can be a practical tool for scholars interested in theatre studies and the history of performing arts to start exploring various existing theatre data projects, and to potentially further extend this inventory in the future.

Several criteria were taken into account when selecting relevant data projects. The geographical focus was limited to Europe ${ }^{3}$ tying in with existing initiatives on a continental scale to make cultural heritage and data available for research and other uses, such as Europeana and the 


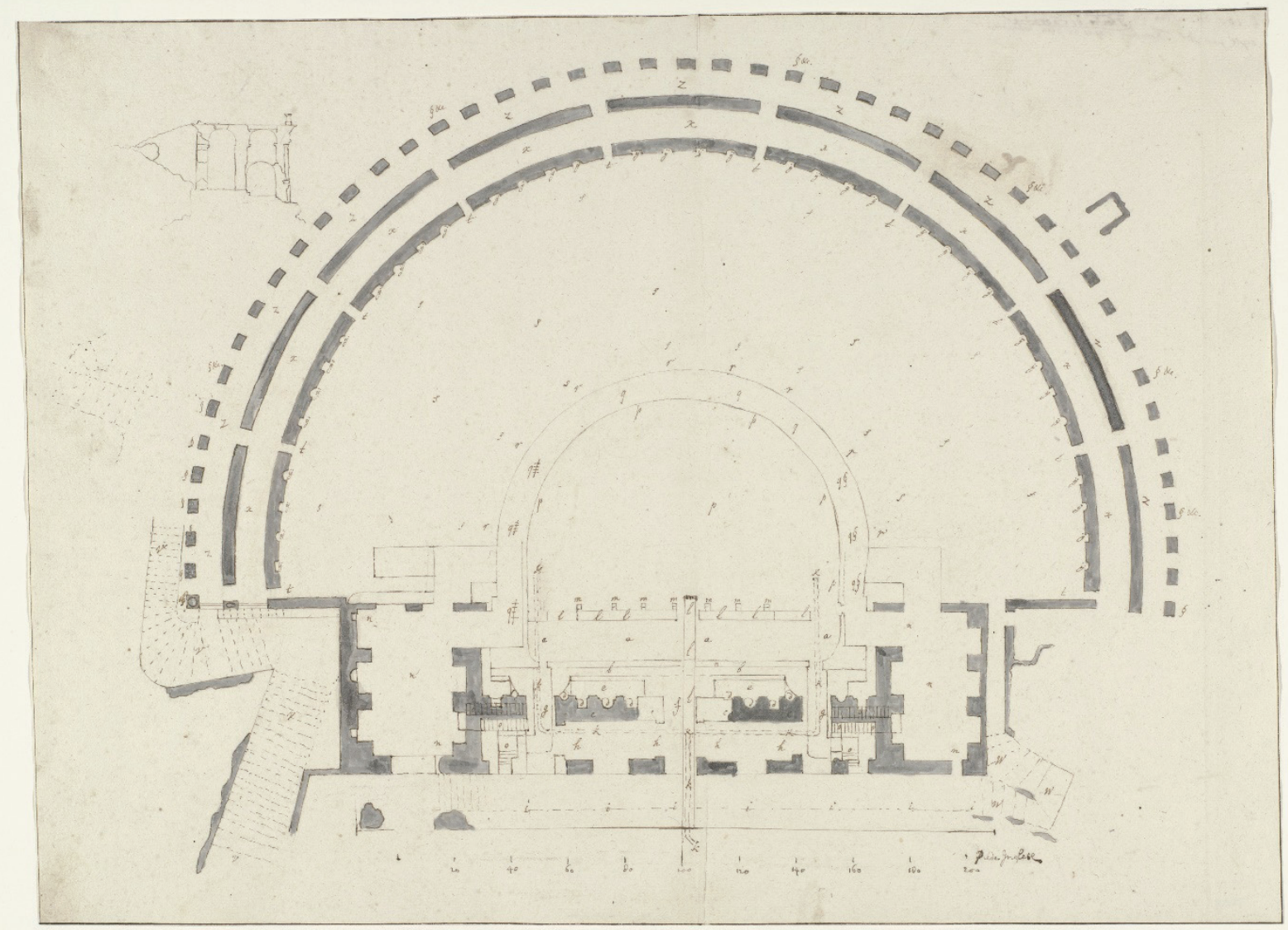

Figure 1. Plan of the theatre of Taormine, anonymous, 1778. Collection Rijksmuseum, http://hdl.handle.net/10934/RM0001.COLLECT.473783.

European research infrastructure DARIAH. ${ }^{4}$ As can be seen in the project overview below, a distinction was made between a database's 'country of origin' (i.e. the country or countries in which it was established, by researchers and/or cultural institutions) and the 'geographical scope' (i.e. the country or countries covered by the collected data). The temporal scope roughly runs from 1600 until the present day. The final inventory nevertheless includes a small number of databases that cover earlier periods too, with one website (the APGRD Productions Database) even going back as early as the mid-fifteenth century in documenting theatrical performances of ancient Greek and Roman dramas, such as those performed in the ancient theatre of Taormina for example (Figure 1). Besides these geographical and temporal selection criteria, it also proved necessary to define the term 'database'. In order to qualify for inclusion in the inventory, a project's data had to be openly accessible online,${ }^{5}$ either through a website or by means of downloadable files. 
Additionally, the data needed to allow for a minimal degree of searchability, either through particular interfaces and query functions, or by simply allowing users to click and scroll their way through the data records. ${ }^{6}$

As the scatteredness of historical data projects precludes a linear search process, we adopted two main search strategies. Firstly, we focused our attention on international research networks and institutes, such as SIBMAS (International Association of Libraries, Museums, Archives and Documentation Centres of the Performing Arts) ${ }^{7}$ and its UK-based counterpart APAC (Association of Performing Arts Collections), ${ }^{8}$ which have ties with numerous data projects in various member countries. Secondly, the websites of relevant data projects often incorporate links and references to other databases, which further propelled the search process along the lines of a 'snowball sampling method'. The Comédie-Française Registers Project was for instance inspired by the earlier CESAR Database. ${ }^{9}$ Another example is that of Les Archives du Spectacle, which mentions the Belgian ASP@ sia project as one of the information sources for its own data collection of theatrical performances. ${ }^{10}$ This also shows the possible overlap between certain projects.

The search process regularly revealed projects that blurred the disciplinary boundaries between various types of performing arts. Several data projects in the overview adopt a rather ambiguous or loose definition of theatre. The CESAR Database for instance explicitly states how its data scope is "all-inclusive, covering plays, operas, ballets, fairground productions, street performances and other incidental theatrical entertainments of all kinds." ${ }^{11}$ While our inventory is based on an inclusive definition of theatre, not all adjacent genres of artistic performance are equally prominent in the final project overview. Genres such as dance, circus or pantomime are currently underrepresented. Furthermore, in terms of the geographical spread, a large part of the listed databases have been developed in and/or cover English-speaking areas. While this observation might indicate the prevalence of the United Kingdom when it comes to historical data collection, it is more probable that this points to biases in the search process, even if we have performed web searches using non-English search terms and language settings in the browser.

The data models underpinning the collected performing arts projects are usually governed by the basic ontological hierarchy of the 'work' ("concerns the elements that never change about a work"), 'production' ("concerns the team that put the work on stage”) and 
'performance' ("concerns the people on stage or in the orchestra pit who perform a certain production of the work on a particular day"), as the Royal Opera House Performance Database describes it. ${ }^{12}$ Based on our explorations, we further distinguish two main types of data models among the performing arts databases: item-oriented and event-oriented. Item-oriented data models are structured around specific items such as venues (buildings, locations), ${ }^{13}$ works (plays, librettos), or persons. Whereas the Royal Opera House Performance Database centers around one particular institution, other databases like the Theatrescapes Research Tool target a multitude of venues as places of performance. Other data projects take the 'work', written or produced by a certain playwright or composer, as a starting point. For example, the Staging Beckett project starts from the works of the Irish playwright to explore the professional productions of Beckett's drama throughout the United Kingdom and Ireland. In contrast to item-oriented data models, the event-oriented data model takes an explicit combination of items as its basic structuring principle. AusStage's definition of an event as a “distinct happening defined by title, date/s and venue" indicates how an event is usually at least made up of a date, a place and a work. ${ }^{14}$ In fact, it can be argued that event-oriented databases combine several item-oriented data models, linking basic entities like 'work', 'person', 'venue' and 'company' that together constitute the performance as an 'event'.

A side effect that we encountered during our effort of compiling performing arts databases was the confrontation with dormant, inactive or abandoned projects, which points to the pressing issue of preservation and curation of digital projects. In general, we can observe two types of institutional frameworks furnishing the data projects that make up our inventory. The majority of the collected databases are either produced within academic programs, often financed with (temporary) project funding, or are set up by particular theatre institutions to 
document and showcase their own history. In either case, one can imagine that there are significant risks for the mid- and long-term sustainability of the data, not only by keeping it securely stored on a server, but also ensuring necessary updates of the data and software. What happens when an academic project is finished and the funding ends? Or when the scholars involved retire ${ }^{15}$ Will database maintenance remain a priority when a cultural host institution faces budget cuts? We do not have readily available solutions to these problems, but the development of a central research infrastructure, sustained by an active community of scholars, to meaningfully connect separate performing arts data collections might help forestall the problem of 'orphaned' datasets. ${ }^{16}$

Lastly, we want to raise a point about how data can be presented, in such ways that it invites scholars and other users to actively engage with the collected material. To what extent does the provider of the data want to serve in an editorial capacity, facilitating or suggesting specific research questions and topics, or even supplying storylines and thematic contexts that can help users make sense of the data? A stimulating example is the relational database Dezède, which clusters and enriches certain of its event records to subsequently present them in freely consultable files or dossiers that function as thematic publications complemented with data visualisations and digitised performance sources. ${ }^{17}$ This procedure, which is monitored by Dezède's editorial committee, proves fruitful to develop thematic cross-sections that facilitate users' engagement with and understanding of the data. Such curatorial interventions can be an interesting model to emulate on a larger scale, if, in the future, solutions can be found for the development of an overarching research infrastructure that can link existing databases. For now, users can already start to find their own way by exploring the rich variety of historical theatre data projects that are gathered in the overview presented here. 
TMG 24 (1/2) 2021

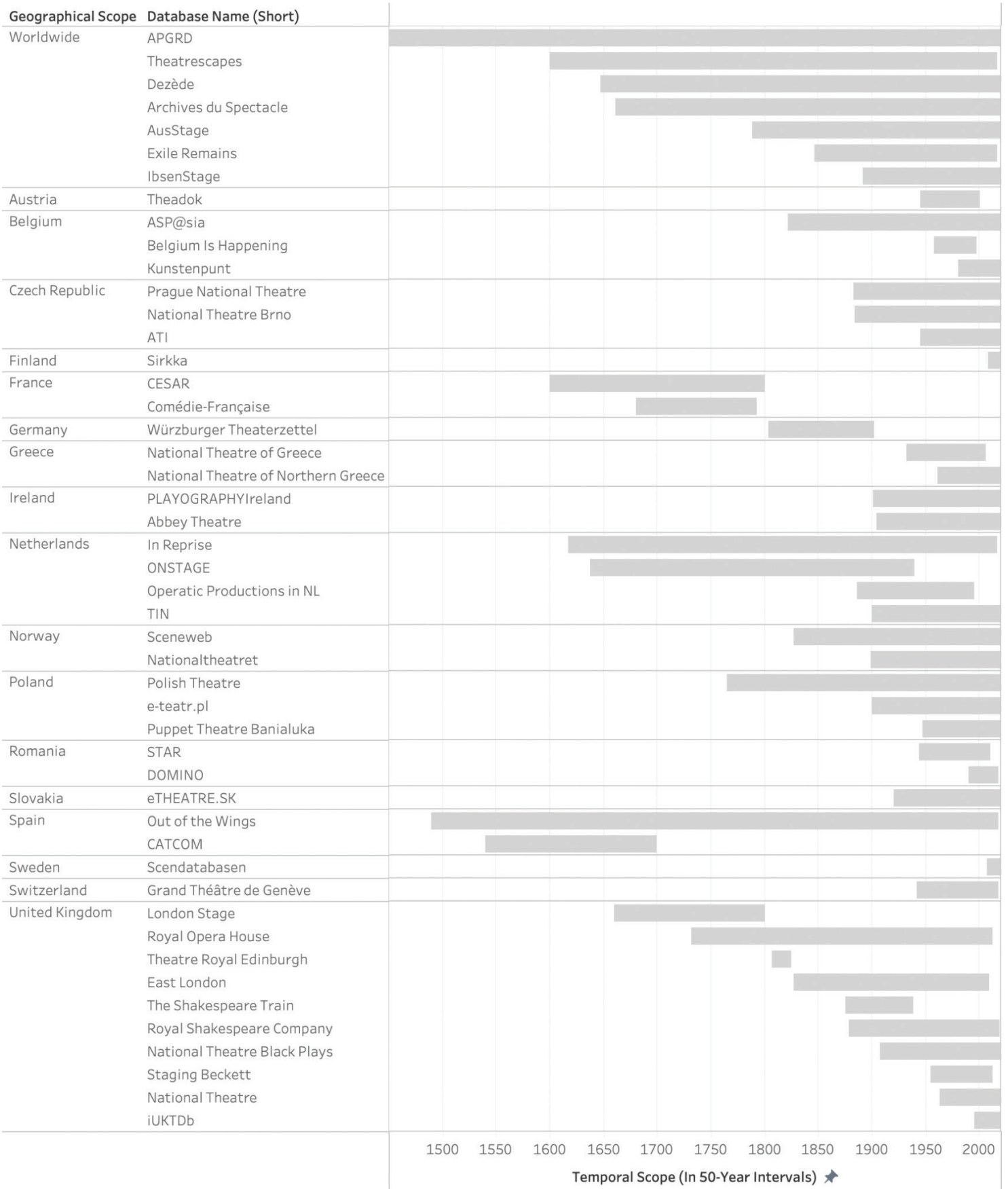

Figure 2. Graph of European theatre databases, sorted according to geographical and temporal scope. In the left column the selected databases are clustered according to their geographical scope. A total of seven data projects are not limited by national boundaries, but adopt a worldwide scope. On the other hand, four databases focus on theatre history within the Netherlands, for example. The datasets in each geographical cluster are also sorted according to the time period covered by their data. The aforementioned APGRD Productions Database, for instance, is displayed as the first dataset with a worldwide scope, because its data collection goes further back in time than the other 'worldwide' databases. While the names of the performing arts databases are displayed in abbreviated form here, the full project names can be found in Table 1, below. The sequence of the databases in Table 1 corresponds with the order of projects in Figure 2. 
Database Name (Long)

APGRD Productions Database

Theatrescapes Research Tool

Dezède

Les Archives du Spectacle

Ausstage

Exile Remains Database

IbsenStage

Theadok

ASP@sia

Belgium Is Happening

Kunstenpunt

Prague National Theatre Repertoire Inventory

National Theatre Brno Archive

ATI's Theatre Productions Database

Sirkka Database

CESAR Database

Comédie-Française Registers Project

Würzburger Theaterzettel

Archive of the National Theatre of Greece

Performance Archive of the National Theatre of Northern Greece

PLAYOGRAPHYIreland

Abbey Theatre's Performance Database

In Reprise

/performance-database/production

Country of Origin http://www.theatrescapes.gwi.uni-muenchen.de/

https://dezede.org/

http://www.lesarchivesduspectacle.net/?

http://www.ausstage.edu.au/pages/browse/

Germany

France

France

Australia

.

https://ibsenstage.hf.uio.no/

https://theadok.at/

http://www.aml-cfwb.be/aspasia/accueil

https://sites.google.com/site/belgiumishappening/hom

http://data.kunsten.be/

http://archiv.narodni-divadlo.cz/

http://stary.ndbrno.cz/o-divadle/online-archiv

http://vis.idu.cz/Productions.aspx

http://sirkusinfo.fi/en/circus-in-finland/sirkka-database

https://cesar.huma-num.fr/cesar2/home.php

ittps://cfregisters.org/\#!/

http://theaterzettel.franconica.uni-wuerzburg.de/

http://www nt-archive.gr/

http://www.ntng.gr/default.aspx?lang=en-GB\&page=23

http://www.irishplayography.com/

ttps:/www abbeytheatre ie/archives/browse performance database/

Norway

Austria

Belgium

Belgium

Belgium

Czech Republic

Czech Republic

Finland

United Kingdom

France

Germany

Greece

Greece

Ireland

ttp://inreprise org/

ONSTAGE: Online Datasystem of Theatre in Amsterdam from the Golden Age to the Present

Operatic Productions in the Netherlands Database

http://www.vondel.humanities.uva.nl/onstage/

TIN Theaterencyclopedie

https://doi.org/10.17026/dans-zcy-g3pt

列:/theaterencyclopedie.nl/wiki/Hoofdpagin

http://sceneweb.no/en/

Sceneweb

Encyclopedia of Polish Theatre

e-teatr.pl

http://forest.nationaltheatret.no/

http://www.encyklopediateatru.pl/

https://e-teatr.pl/archiwum

http://www.cyfrowa-banialuka.pl/

Digital Archive Puppet Theatre Banialuka

STAR Database: Repertory Theatre in Romania

DOMINO Database: Premiere Music and Choreography in Romania

tttp://www.cimec.ro/Teatre/Star_Home_eng.htm

http://www.cimec.ro/scripts/Muzica/Premiere/selPREM. asp

http://etheatre.sk/du_vademecum/

Out of the Wings: Spanish and Spanish American Theatres in Translation

CATCOM: Database of Comedies Mentioned in Theatrical Documentation

http://www. outofthewings.org/

http://catcom.uv.es/consulta/

http://www.scendatabasen.se/Default.aspx

http://archives.geneveopera.ch/accueil

Les Archives du Grand Théâtre de Genève

http.//archives.geneveopera.ch/accuei

Ireland

Netherlands

Netherlands

Netherlands

Netherlands

Norway

Norway

Poland

Poland

Poland

Romania

Romania

Slovakia

United Kingdom

Spain

Sweden

Switzerland

United Kingdom

http://www.rohcollections.org.uk/Performances.aspx

http://digital.nls.uk/playbills/index.html

Playbills of the Theatre Royal Edinburgh

East London Theatre Archive

The Shakespeare Train

Royal Shakespeare Company Performances

National Theatre Black Plays Archive

Staging Beckett

National Theatre Archive

Internet UK Theatre Database

http://www.elta-project.org/

http://www ellenterryarchive hull.ac.uk/shakespeare

http://collections.shakespeare.org.uk/search/rsc-performances

http://www.blackplaysarchive.org.uk/

https://www.reading.ac.uk/staging-beckett/

http://catalogue.nationaltheatre.org.uk/CalmView/Default.aspx?

https://www.uktw.co.uk/archive/

Table 1. List of European theatre databases, sorted in accordance with Figure 2.

\section{Notes}

1 http://www.create.humanities.uva.nl/. All web addresses mentioned in the endnotes have been accessed 6 September, 2021.

2 Within the CREATE research program itself, several databases on these performing arts disciplines are maintained, namely ONSTAGE (on theatre), the Operatic Productions in the Netherlands Database (on opera), the Felix Meritis Concert Programs Database (on music) and Cinema Context (on film). See https://

brill.com/view/journals/rdj/5/2/rdj.5.issue-2.xml for data papers on these and other performing arts datasets. 
3 While the presented inventory includes several projects founded in Europe but with a worldwide data scope, no similarly expansive databases were included that were established outside Europe, apart from one exception: the Australian performance database AusStage is included in the inventory, in part because it served as a model for the development of the Norway-based IbsenStage. Other non-European theatre sources, such as the wellknown Internet Broadway Database (https://www.ibdb.com/) for instance, are not included in our overview. DARIAH-EU is a European Research Infrastructure Consortium (ERIC) for the Arts and Humanities, which supports research and teaching in E-Science: https://www.dariah.eu/. For Europeana, see https://www. europeana.eu/nl.

5 A (partially) commercial database like Operabase (https://www.operabase.com/en), for example, is therefore not included in our overview.

6 Consequently, the inventory is not limited to relational databases, but also contains projects that present their performance data in 'flat' lists and tables. One example in this respect is the Würzburger Theaterzettel project, which is made up of more than 9500 digitised playbills that are listed and can be searched according to three main categories (performance date, title of performance and people involved).

7 http://www.sibmas.org/.

8 http://www.performingartscollections.org.uk/.

9 https://www.cfregisters.org/\#!/projets-amis/cesar.

10 https://www.lesarchivesduspectacle.net/?qui_sommes_nous.

11 See the introductory statement about the database's content and scope on the homepage: https://cesar. huma-num.fr/cesar2/home.php.

12 http://www.rohcollections.org.uk/Performances.aspx.

13 Regarding performance venues, some databases also exist that center entirely around the architectural history of theatre buildings, and thereby constitute interesting supplements to the collected performance-related data projects in our overview. Examples include the Theatres Trust Database (https://database.theatrestrust.org. uk/) and the European Theatre Architecture Database (https://www.theatre-architecture.eu/db.html).

14 http://www.ausstage.edu.au/pages/learn/about/data-models.html.

15 An example in this regard is the aforementioned CESAR Database, which, after the project's initial funded development at Oxford Brookes University in the early 2000s, became property of another university later on. When looking at an arbitrary data entry (for example: https://cesar.huma-num.fr/cesar2/titles/titles. php?fct=edit\&script_UOID=166333), it becomes clear that the database website has technical problems and is not actively and regularly maintained. Equally telling is the case of the postcolonial Exile Remains 
Database, of which the original website already disappeared in the period between the start of our inventory efforts and this publication. At this moment, this data project's content can be traced back through the Internet Archive’s Wayback Machine: https://web.archive.org/web/20181127065743/http://www. hispanicexile.bham.ac.uk/.

16 The storing of (static) datasets at trusted data repositories, and the description of the composition of the dataset and how it was collected in a data paper, is one way to at least preserve the data and secure opportunities for future re-use. See for example: Thunnis van Oort and Julia Noordegraaf, “Structured Data for Performing Arts History: An Introduction to a Special Issue of Data Papers”, Research Data Journal for the Humanities and Social Sciences 5, 2 (2020): 1-12, doi: https://doi.org/10.1163/24523666-bja10008, and the various data papers in this special issue.

17 For a list of the Dezède dossiers, see https://dezede.org/dossiers/.

\section{Biographies}

Vincent Baptist is a $\mathrm{PhD}$ candidate working at the Department of History within the Erasmus School of History, Culture and Communication (Erasmus University Rotterdam). His doctoral research is embedded in the European HERA project 'Pleasurescapes: Port Cities' Transnational Forces of Integration'. He previously worked as a Pre PhD fellow within the digital humanities research program CREATE (University of Amsterdam), where his research was partially linked to the CLARIAH Amsterdam Time Machine project.

Julia Noordegraaf is professor of digital heritage in the Department of Media Studies (University of Amsterdam) and director of the Amsterdam Centre for Cultural Heritage and Identity, where she leads the digital humanities research program CREATE. Noordegraaf acts as Media Studies board member in CLARIAH, the national infrastructure for digital humanities research funded by the Netherlands Organization for Scientific Research (NWO).

Thunnis van Oort is a historian interested in the use of digital sources and methods in humanities research. He works as post-doctoral researcher at Radboud University on the construction of a database of the population of Suriname between 1830 and 1950. Previously, he participated in the digital humanities research program CREATE of the University of Amsterdam and at Oxford Brookes University in the AHRC-funded project 'European Cinema Audiences'. He is editor of the Cinema Context database. 


\section{TMG Journal for Media History}

Volume 24 No $(1 / 2) / 2021$

\section{DOI}

https://dx.doi.org/10.18146/tmg.806

\section{PUBLISHER}

Netherlands Institute for Sound and Vision

\section{COPYRIGHT}

Each article is copyrighted (c) by its author(s) and is published under license from the author(s). When a paper is accepted for publication, authors will be requested to agree with the Creative Commons Attribution 4.0 International License. 